\title{
Investigation on the Magnetic Field Characteristics for Nuclear Power Half Speed Turbo-generator with Negative Sequence Component
}

\author{
Dong Chuanyou $^{1,2, a}$, Ge Baojun ${ }^{2, a}$, Liang Weiyan ${ }^{1, b}$ and Tao Dajun ${ }^{2, a}$ \\ (1. School of Electrical Engineering and Automation, Harbin Institute of \\ Technology, Harbin 150001, Heilongjiang Province, China; \\ 2. College of Electrical and Electronic Engineering, Harbin University of Science \\ and Technology, Harbin 150080, Heilongjiang Province, China) \\ ('dcy131086@163.com, $\left.{ }^{b} 4502921 @ 163 . c o m\right)$
}

\begin{abstract}
Based on investigation on basis of physical process of the motor running under different negative sequence, calculation simulation model for steam turbine generator field was established on a $1266 \mathrm{MW}$ half speed steam turbine generator for nuclear power generation, and according to time-step finite element electromagnetic theory, the 2-d finite element mathematical model is established. According to the numerical method, the magnetic field distributions inside the motor at the rated running state, with 1\%IN, $2 \% I N, 3 \% I N, 4 \% I N$ and $5 \%$ IN negative sequence current were calculated. Based on the comparison and analysis of the magnetic fields inside the motor, influence of the negative sequence component proportion on the magnetic field distribution was investigated. The results could provide the reference for the design of operation and protection scheme of the generator.
\end{abstract}

Keywords: Turbo-generator; nuclear power generator; magnetic field; negative sequence component

\section{Introduction}

With the development of nuclear power technology, the performance of turbogenerator requires to be enhanced. In order to improve its economic performance, capacity of large turbine generator is increasing, and the safety and stability is the focus of experts and scholars attention [1-3].

With asymmetric load (such as the large capacity of single phase smelting furnace, electric traction locomotives, etc.), or abnormal state such as short circuit and open-phase operation, the electric power system can cause asymmetry of generator load [4-5]. The negative sequence components in asymmetrical load will produce two times of reverse rotating magnetic field with the synchronous speed, and induces the distortion of magnetic field, which will cause the periodic change of electromagnetic force to generator rotor and electromagnetic torque, thus the ripple of generator torque. Running in such conditions for long time, the life of the generator can be reduced, and the safe and reliable operation of the generator can also be affected. Hence, investigation to characteristics of the magnetic field for the steam turbine generator with negative sequence component are of significance to evaluation of running of large steam turbine generator with negative sequence and design of relay protection scheme for its running with negative sequence time.

Domestic and foreign scholars have done a lot of valuable research work on characteristics of magnetic field and electromagnetic torque of large steam turbine generator running with negative sequence. In according to analysis on distribution of 
negative sequence current with ear thing fault occurring in the small current grounding system, methods based on negative sequence over-current protection, the negative sequence directional protection and transient energy conservation have been proposed by Zeng et al. [6].Dong gave a systematic research on the mathematical model for numerical prediction of operation ability of steam turbine generator running with negative sequence, analysis method and steady and transient running ability [7].For a $150 \mathrm{MW}$ air-cooled turbine generator, a two-dimensional mathematical model of electromagnetic field and temperature field were established, eddy current loss and temperature rise on the rotor caused by the negative sequence current(steady state) was calculated for the motor running with the asymmetric three-phase load [8].With analytical method for electromagnetic field, Feng characterized the negative sequence current, zero sequence current and the air-gap magnetic field induced by the negative and zero sequence current in stator of the turbo generator at the steady state of short circuit midpoint [9]. Tai and Zhu investigated the effect of the change of electric parameters the turn-to-turn short circuit on relay protection. It was found that when inter-turn short circuit fault occurred, the second harmonic current and unit transverse differential current in motor rotor have great changes with the increase of number of turns with short circuit, hence reliable protection scheme build based on this can take action efficiently [10]. However, related research on the influence of negative sequence current conducted by foreign scholars showed slightly different results. T. Bach studied the calculation method of negative sequence current in the rotor damper bar, and measured the current through the experiment of generic rotor [11].In the study of negative sequence loss in steam turbine generator, Riley et al. gave a thorough analysis on the establishment of the model and the determination of boundary conditions, and also a emphatically analysis on the important role of the flow path to the establishment of the negative sequence current article damping [12]. In the case of two phase short circuit, eddy current loss on the surface of the rotor was analyzed to a $300 \mathrm{MVA}$ steam turbine generator with the finite element method, and also the force situation of rotor slot wedge was calculated [13]. All of the work above is of great significance for design, operation and protection of large steam turbine generator.

Although some valuable rules and conclusions on protection scheme design, temperature field and negative sequence current have been given for the large steam turbine generator running with negative sequence, analysis on the basic physical process of negative sequence field and torque calculation of the electromagnetic in operation process with negative sequence were less involved accurately. Additionally, most of the current literature is focused on negative sequence problem in the poles steam turbine generator, while half speed steam turbine generator for nuclear power generation is 4 pole structures, and the influence of negative sequence on the operation process of rotor is different from that on the poles [14]. Hence, it is necessary for systematic analysis on the characteristics of magnetic field on the large steam turbine generator for nuclear power generation running with negative sequence, which could provide the reference for the design of operation and protection scheme of the generator.

In this paper, based on the basic theory of energy conversion, basis of physical process of the motor running under different negative sequence was investigated in a $1266 \mathrm{MW}$ half speed steam turbine generator for nuclear power generation, and according to timestep finite element electromagnetic theory, the2-d finite element mathematical model is established. According to the numerical method, the magnetic field distributions inside the motor at the rated running state, with $1 \% \mathrm{IN}, 2 \% \mathrm{IN}, 3 \% \mathrm{IN}, 4 \% \mathrm{IN}$ and $5 \% \mathrm{IN}$ negative sequence current were calculated. Based on the comparison and analysis of the magnetic fields inside the motor, influence of the negative sequence component proportion on the magnetic field distribution was investigated. 


\section{The Physical Process with Negative Sequence Component}

Based on the basic motor theory, according to the symmetrical component method, when three-phase armature current of the motor was asymmetric, the asymmetrical three phase current could be decomposed into three groups of symmetry current including positive sequence current, negative sequence current and zero sequence current. Air-gap magnetic field and leakage magnetic field were set up respectively by each phase of the load current. A synthesized magnetomotive force, which was with constant amplitude and rotated synchronously and homonymously with the rotor, was produced in the stator with positive sequence component of the electric current. As shown in Figure 1, the synthesized magneto motive force was expressed in the rotation vector, and the endpoint locus was circular.

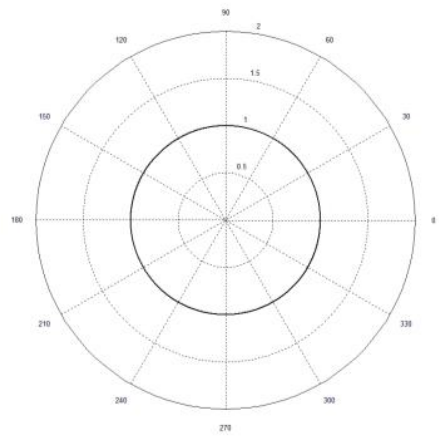

\section{Figure 1. Stator Magnetic Motive Force Path with Only Positive Sequence} Currents

Seen from Figure 2 and Figure 3, compared with the positive sequence component current, when the armature winding including the negative sequence component, the rotation direction of synthetic magneto motive force was opposite, and the rotational speed was the same as the positive sequence component current. The trajectory of motor stator synthesis magneto motive force changed. With the increase of negative sequence component, the magneto motive force trajectory appeared serious distortion gradually.

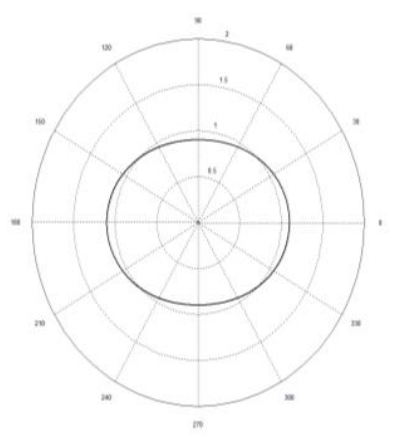

\section{Figure 2. Stator Magnetic Motive Force Path with 5\%INnegative Sequence Currents}

Contrast analysis Figure 1, Figure 2 and Figure 3, with the increase of negative sequence current component, the distortion of the stator magneto motive force trajectory was serious increasingly. The negative sequence component not only changed the shape of the magneto motive force endpoint trajectory, but also changed the amplitude of magneto motive force amplitude. Because of the distortion of the magnetic field, the electromagnetic force of the generator rotor emerged cyclical change. Eventually, electromagnetic torque caused a cyclical change, leading to the generator torque ripple. 


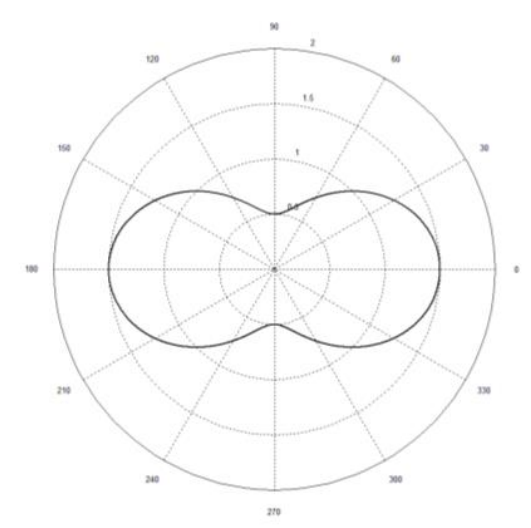

Figure 3. Stator Magnetic Motive Force Path with $50 \%$ IN Negative Sequence Currents

\section{Model of Nuclear Power Half Speed Turbo-generator}

\subsection{Simulation $M$}

In this paper, a nuclear power half speed steam turbine generator with $1226 \mathrm{MW}$ was selected as an example. The time step finite element calculation mode was established by the field - road coupling method, the main parameters of the motor as shown in Table1.

Table 1. Parameters of the Nuclear Power Half-speed Turbo-generator

\begin{tabular}{cc||cc}
\hline Parameter & Value & Parameter & Value \\
\hline$P_{\mathrm{N}} / \mathrm{MW}$ & 1226 & $\mathrm{n}_{\mathrm{N}} / \mathrm{rpm}$ & 1500 \\
Rated power factor & 0.9 & $I_{\mathrm{fN}} / \mathrm{A}$ & 9265 \\
& & & \\
$U_{\mathrm{N}} / \mathrm{kV}$ & 24 & $f_{\mathrm{N}} / \mathrm{Hz}$ & 50 \\
$I_{\mathrm{N}} / \mathrm{A}$ & 33847 & $I_{\mathrm{f} 0} / \mathrm{A}$ & 3295 \\
& & & \\
\hline
\end{tabular}

\subsection{The finite Element Model and Boundary}

The straight line part of the steam turbine generator was calculated by using two dimensional transient fields, considering the symmetry of motor structure, the solving area of electrical geometry model and grid subdivision model are as shown in Figure 4 and Figure 5, respectively. Ignoring the motor stator core eddy current and the displacement current, the circuit equation and electromagnetic field equation is adopted to calculate the stator winding end impedance. The boundary value form of the twodimensional transient electromagnetic field equation can be obtained by Maxwell's electromagnetic field equations.

$$
\left\{\begin{array}{c}
\frac{\partial}{\partial x}\left(\frac{1}{\mu} \frac{\partial A_{z}}{\partial x}\right)+\frac{\partial}{\partial_{y}}\left(\frac{1}{\mu} \frac{\partial A_{z}}{\partial y}\right)=-J_{z} \\
A_{z} \mid A B=0 \\
A_{z}\left|O A=-A_{Z}\right| O B
\end{array}\right.
$$

Where $\mu$ is the magnetic permeability of materials, $J_{z}$ is the source current density, $A_{z}$ is vector magnetic potential. 


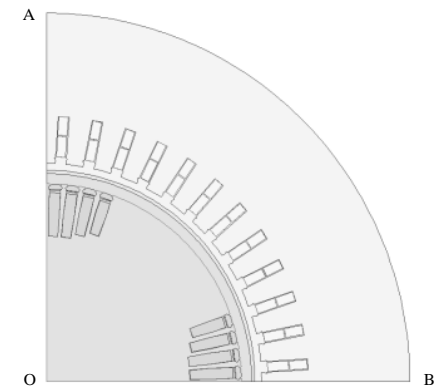

Figure 4. Solve Region of the Generator

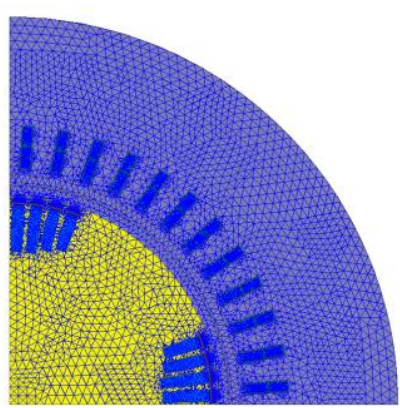

Figure 5. Mesh Model of the Solve Region

\section{Analysis of the Turbo-generator Field}

\subsection{Magnetic Field Distribution with Rated Condition}

According to the given parameters of the nuclear power half speed steam turbine generator, the initial conditions of a motor rated running state were supplied. The positive sequence three-phase current rating accessed the three-phase winding of motor, and the rotor initial phase angle and excitation current rating were given. numerical calculation was carried out on the solve regional of motor, and the motor running state was determined by the stator voltage and the current size and phase relationship, which is as shown in Figure 6.

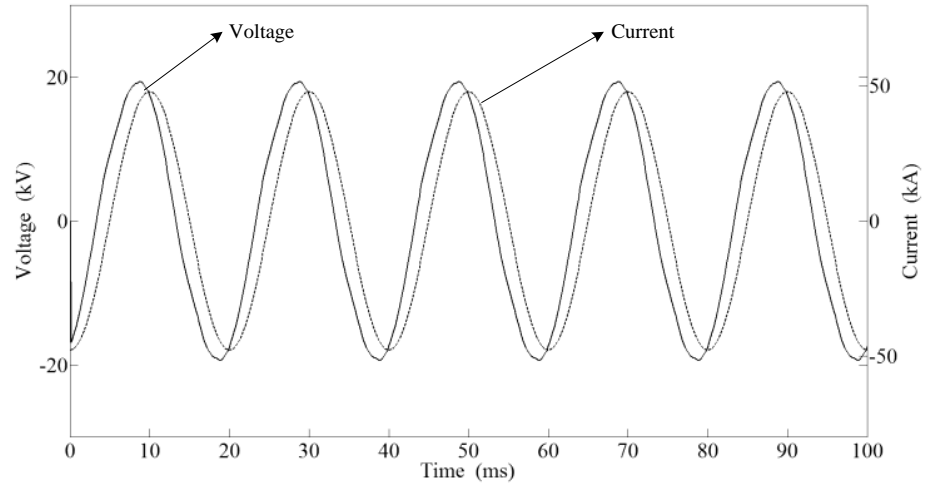

Figure 6. Rated Voltage and Current

Figure 7 shows that the different time magnetic field distribution of nuclear power half speed steam turbine generator under rated running state.

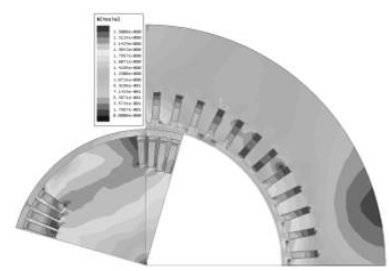

a) $t=0.02 \mathrm{~s}$

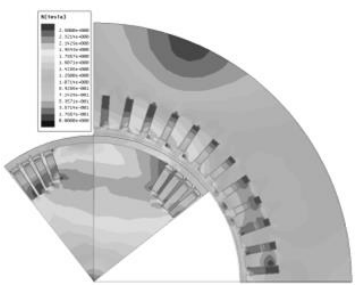

b) $t=0.026 \mathrm{~s}$ 

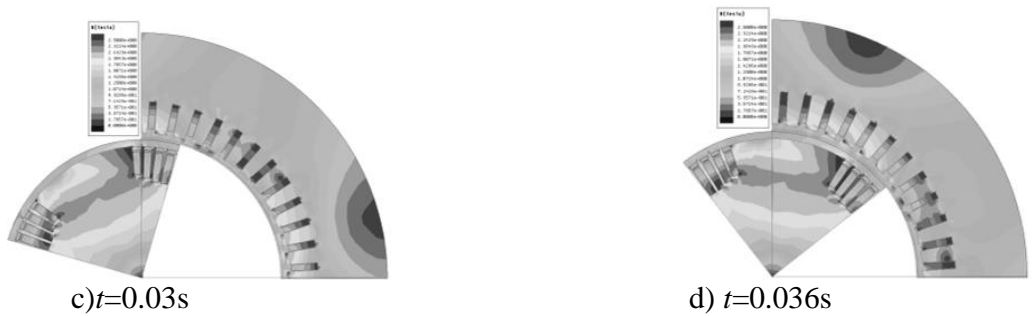

d) $t=0.036 \mathrm{~s}$

\section{Figure 7. Flux Density Distribution with Rated Load at Different Moments}

Contrast the flux density distribution at different moment in Figure 7, under the rated condition, the flux density distribution state was the same in the rotor area at any running moment. This is because that the generator is in the rated condition, the armature winding only had the positive sequence current, the synthesis stator magnetic field and the main pole magnetic field were at the same rotor speed, the magneto motive force of stator and rotor remained relatively static. So compared with the rotor, the motor synthetic magneto motive force was in the static state. Flux density distribution rule of the machine rotor is the same at any motor running moment.

\subsection{The Magnetic Field Distribution with the Negative Sequence Component}

The asymmetry of the machine load was due to the external causes, and the armature current would contain the negative sequence component. The negative sequence component current was directly added into the load current as the initial incentive conditions in the calculation process of motor magnetic field distribution at different moment, which is as shown in Figure 8.

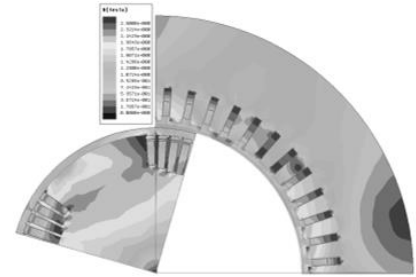

a) $t=0.02 \mathrm{~s}$

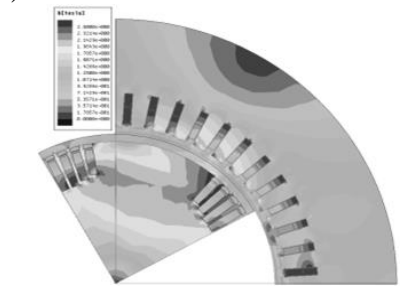

c) $t=0.025 \mathrm{~s}$

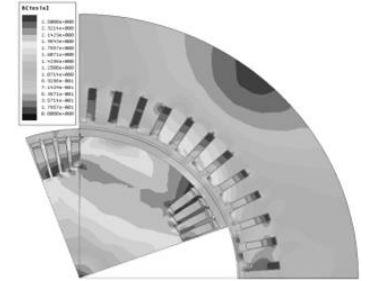

b) $t=0.024 \mathrm{~s}$

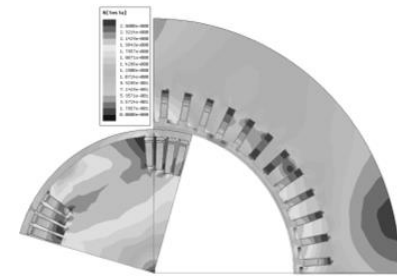

d) $t=0.03 \mathrm{~s}$

\section{Figure 8. Flux Density Distribution with Negative Sequence Currents at} Different Moments

Figure 8 shows that the flux density distribution cloud image of motor solve regional at four moments in the half cycle. Contrast the flux density distribution at the different moment, the flux density of the rotor tooth angle site decreased gradually from 0.02 seconds to the minimum 0.025 seconds, and then gradually increase. The flux density presented a cyclical change rule, which was in accordance with the theoretical analysis results of Figure 2 and Figure 3.

Seen from Figure 7 and Figure 8, due to the existence of negative sequence component, the rotor flux density distribution law was different from flux density distribution in the rated running state, especially the flux density had a marked shift 
in big tooth rotor position. In order to define the existence of the negative sequence component influence on the generator magnetic field distribution, the magnetic field distribution of different negative sequence component at the same time were carried out, which is as shown in Figure 9.

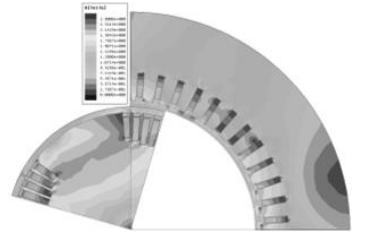

a) $I_{2}=1 \% I_{\mathrm{N}}$

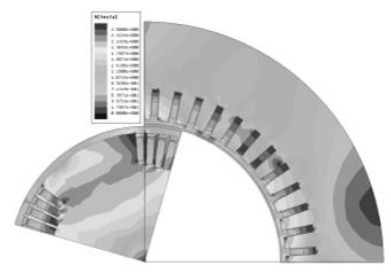

c) $I_{2}=3 \% I_{\mathrm{N}}$

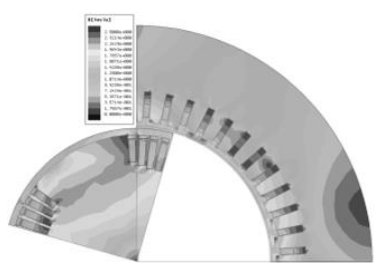

d) $I_{2}=4 \% I_{\mathrm{N}}$

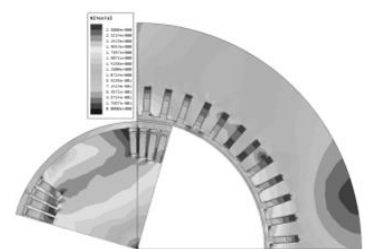

b) $I_{2}=2 \% I_{\mathrm{N}}$

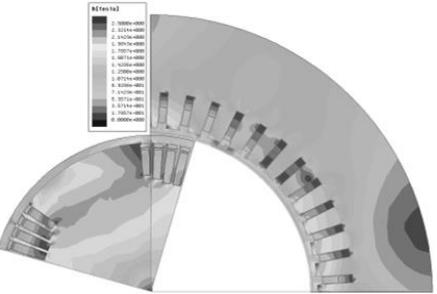

e) $I_{2}=5 \% I_{\mathrm{N}}$

Figure 9. Flux Density Distribution with Different Negative Sequence Currents at the Same Moment

Seen from Figure 9, with the increase of negative sequence component, the rotor flux density of big teeth area decreased, but the flux density of large tooth angle increased gradually. This is suggested that the magnetic field distortion was caused by negative sequence component, which changed the rotor flux density distribution. And with the increase of negative sequence component, the influence of the flux density distribution gradually increased. Comparison of Figure 7a and Figure 9e, when the negative sequence component current reached 5\% of the rated current, the rotor flux density distribution and the rated flux density distribution is obvious different, especially in the running state of the rotor big tooth root parts. Due to the influence of negative sequence component, round rotating magnetic field at the amplitude constant occurred distortion, which made some parts of the flux density increase and the other decrease.

\section{Conclusion}

Based on investigation on basis of physical process of the motor running under different negative sequence and theoretical analysis of synthesis magneto motive force in the stator running with negative sequence, the magnetic field distributions at the rated running state, with $1 \% \mathrm{IN}, 2 \% \mathrm{IN}, 3 \% \mathrm{IN}, 4 \% \mathrm{IN}$ and $5 \% \mathrm{IN}$ negative sequence current were calculated.

When there is a negative sequence component in the generator, the magnetic field distribution in rotor change periodically. Especially, flux densities are significantly increased in large gear tooth root because of the influence of the negative sequence component.

\section{References}

[1] H. Wang, "The effect of impact load on the operation of steam turbine generator", North China Electric Power University, (2012), pp. 1-5.

[2] C. P. Riley, "Negative sequence losses in turbine generator rotors", ICEMS2012, Marseille, France: IEEE Press, (2012), September 2-5, pp. 1364-1368.

[3] T. Bach, "Determining negative sequence currents of turbine generator rotors", ICEMS2009, Tokyo, Japan: IEEE Press, (2009), November 15-18, pp. 1-6. 
[4] M. G. Pantelyat, "Finite element analysis of electromagnetic field and losses in a turbo generator rotor, CEM, Aachen, Germany : VDE, 4-6 April, $2006: 1-2$.

[5] M. G. Pantelyat, "Electromagnetic forces in synchronous turbo generator rotor slot wedges", ISTET2011, Klagenfurt, Austria: IEEE Press, (2011) July 25-27, pp. 1-4.

[6] X. Zeng, X. Yin and Z. Zhang, "Study for negative sequence current distributing and ground fault protection in middle voltage power systems", Proceeding of the CSEE, vol. 21, no. 6, (2001), pp. 85-90 (in Chinese).

[7] J. Dong, "The Study on the Million Kilowatt Turbine Generator Negative Sequence Running Capability", Zhejiang University, (2006).

[8] W. Li, J. Sun and H. Sun, "Calculation and Analysis of Eddy Loss and Temperature Field in Rotor of Synchronous Generator under Steady State and Negative Sequence", Transactions of China Electro technical Society, (in Chinese), vol. 27, no. 9, (2012), pp. 174-182.

[9] E. Feng, "The currents produced in the solid rotor of turbo generator and the air gap magnetic fields both by the stator negative sequence current and the zero sequence on the steady state of the line to line grounded short circuit", Proceeding of the CSEE, (in Chinese), vol. 22, no. 9, (2002), pp. 99-104.

[10] N. Tai and J. Zhu, "New Protection Scheme for Asymmetrical Faults in Large Ultra-supercritical turbogenerators", Automation of Electric Power Systems, (in Chinese), vol. 30, no. 20, (2006), pp. 54-58.

[11] S. Fan, "Analysis of stability for large and medium-sized hydro-generating unit", Proceeding of the CSEE, (in Chinese), vol. 32, no. 9, (2012), pp. 140-148.

[12] H. Fang, C. Xia and J. Xiu, "Analysis of generator electro-magnetic torque on armature winding interturn short circuit fault", Proceedings of the CSEE, (in Chinese), vol. 27, no. 15, (2007), pp. 83-87.

[13] B. Ge, Y. Liang and J. Wen, "Motor learning", Beijing: China Electric Power Press, (2010).

[14] J. Gao, X. Wang and F. Li, "The analysis of the ac motor and its system", Beijing: Tsinghai University Press, (2005). 